\title{
Transient Multiphysics with MAMMOTH and Bison
}

\author{
Adam X Zabriskie
}

July 2019

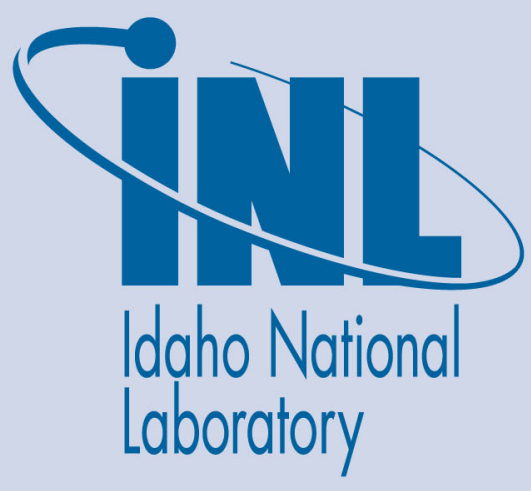

The INL is a U.S. Department of Energy National Laboratory operated by Battelle Energy Alliance 


\title{
Transient Multiphysics with MAMMOTH and Bison
}

\author{
Adam X Zabriskie
}

July 2019

Idaho National Laboratory Idaho Falls, Idaho 83415

http://www.inl.gov

\author{
Prepared for the \\ U.S. Department of Energy \\ Under DOE Idaho Operations Office \\ Contract DE-AC07-05ID14517
}




\title{
Transient Multiphysics with MAMMOTH and Bison
}

\author{
Adam X. Zabriskie, PhD
}

Nuclear Science \& Technology at EROB

\section{MAMMOTH \& LEU TREAT}

TREAT reactor fuel is heterogeneous with $\mathrm{UO}_{2}$ fuel particles dispersed in a graphite matrix. Fission energy is largely deposited in $\mathrm{UO}_{2}$ raising the temperature; heat energy then conducts into the graphite. Both materials have different mechanisms providing temperature feedback. Low enriched uranium (LEU) changes the temperature feedback mechanism in $\mathrm{UO}_{2}$ adding stronger feedback. MAMMOTH simulation couples temperature and neutron feedback allowing the heterogeneous fuel materials to be at different temperatures, which affects feedback from either the $\mathrm{UO}_{2}$ or graphite.
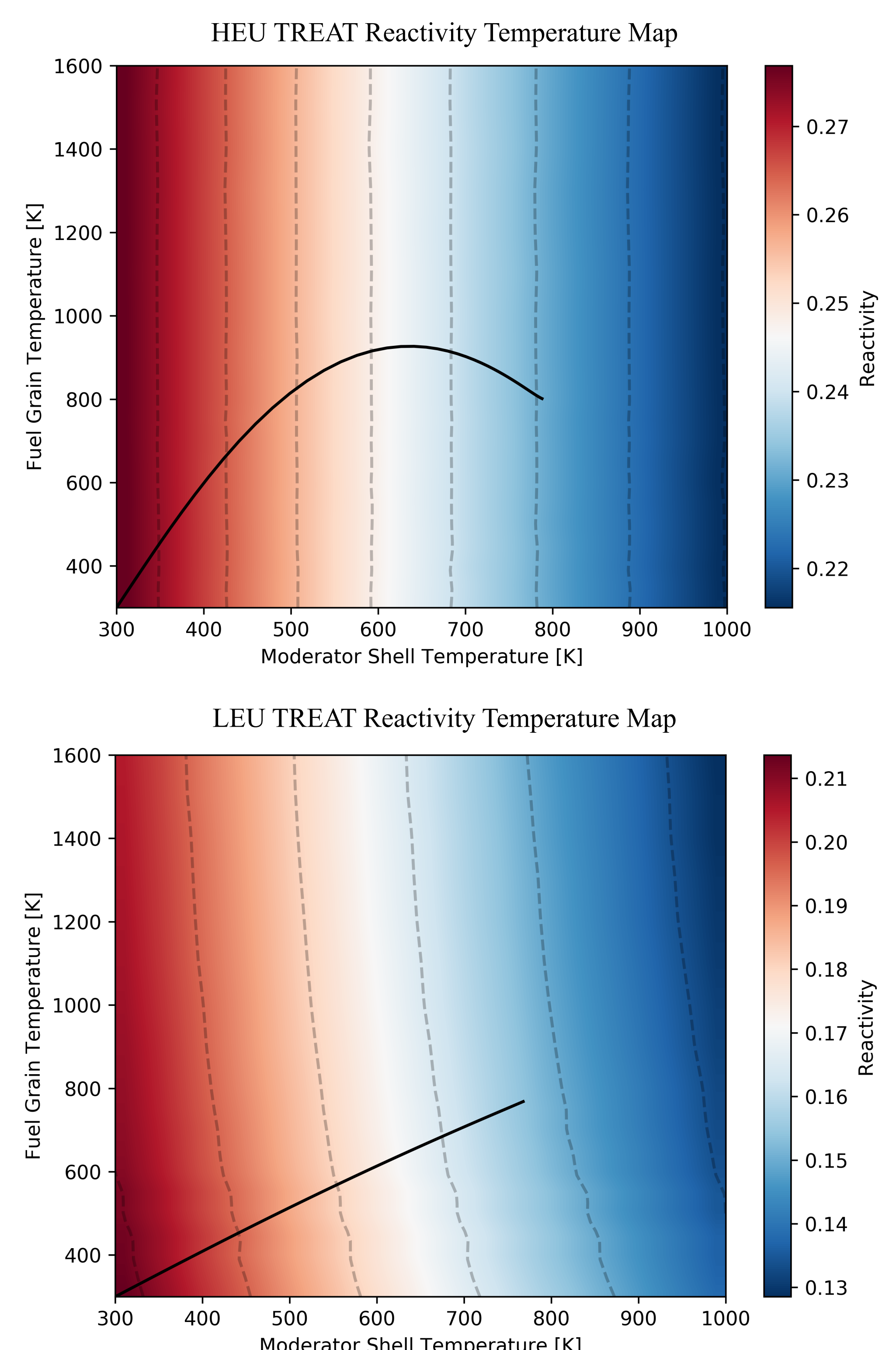

- Can LEU converted TREAT produce a self-limiting pulse that is the same as an HEU fueled TREAT?

- Can LEU converted TREAT match HEU pulse characteristics to produce similar pulses?

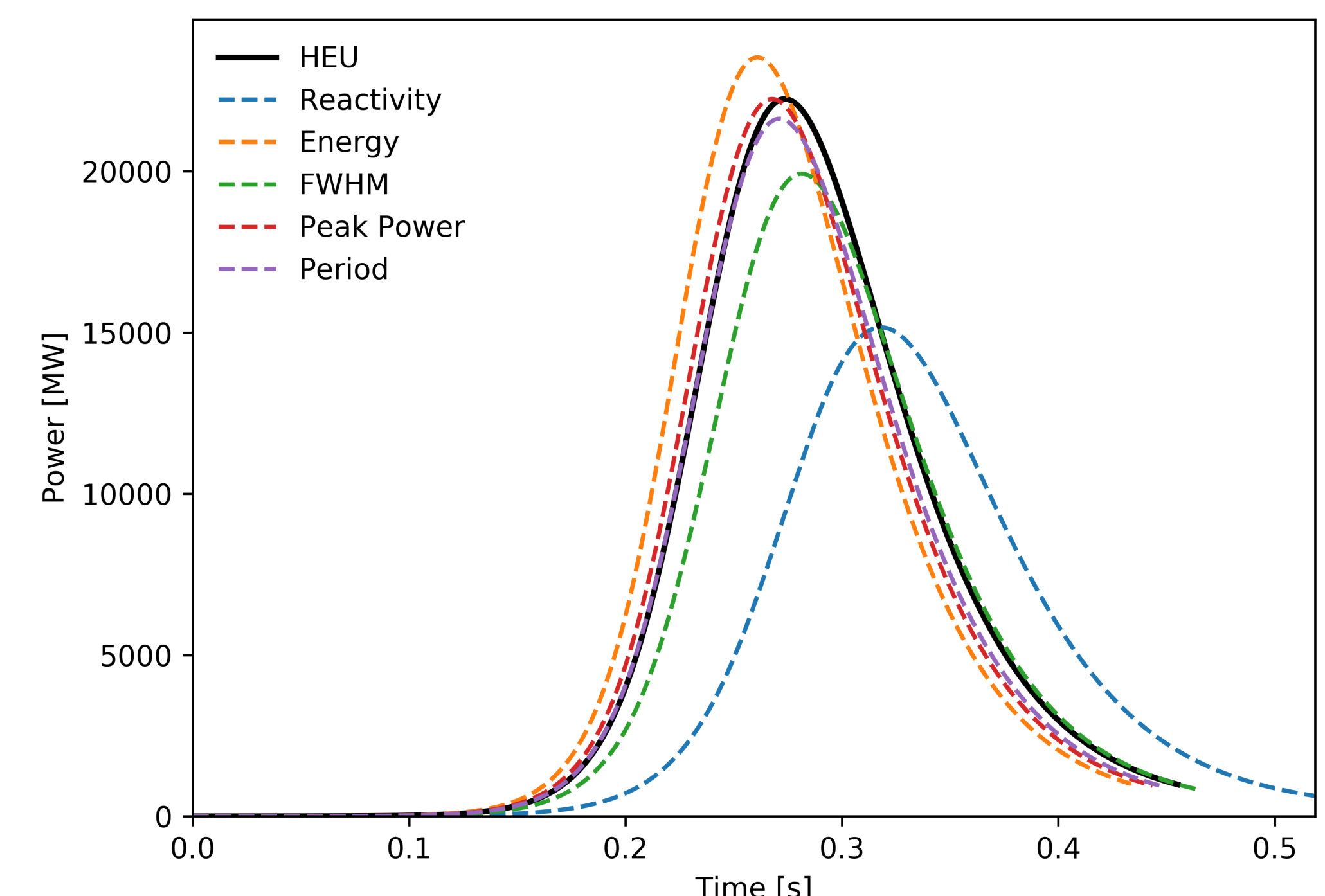

\section{Bison \& Metallic Fuel}

Benchmark simulations provide insight into current capabilities and future development needs. Currently, Bison is being benchmarked for metallic fuel simulations. Part of the benchmarks dea with historic transient experiments conducted in EBR-II and TREAT. Benchmarks are multiphysics including thermal and mechanical interaction along with species diffusion where properties are available. Future work involves other experiments with different cladding.

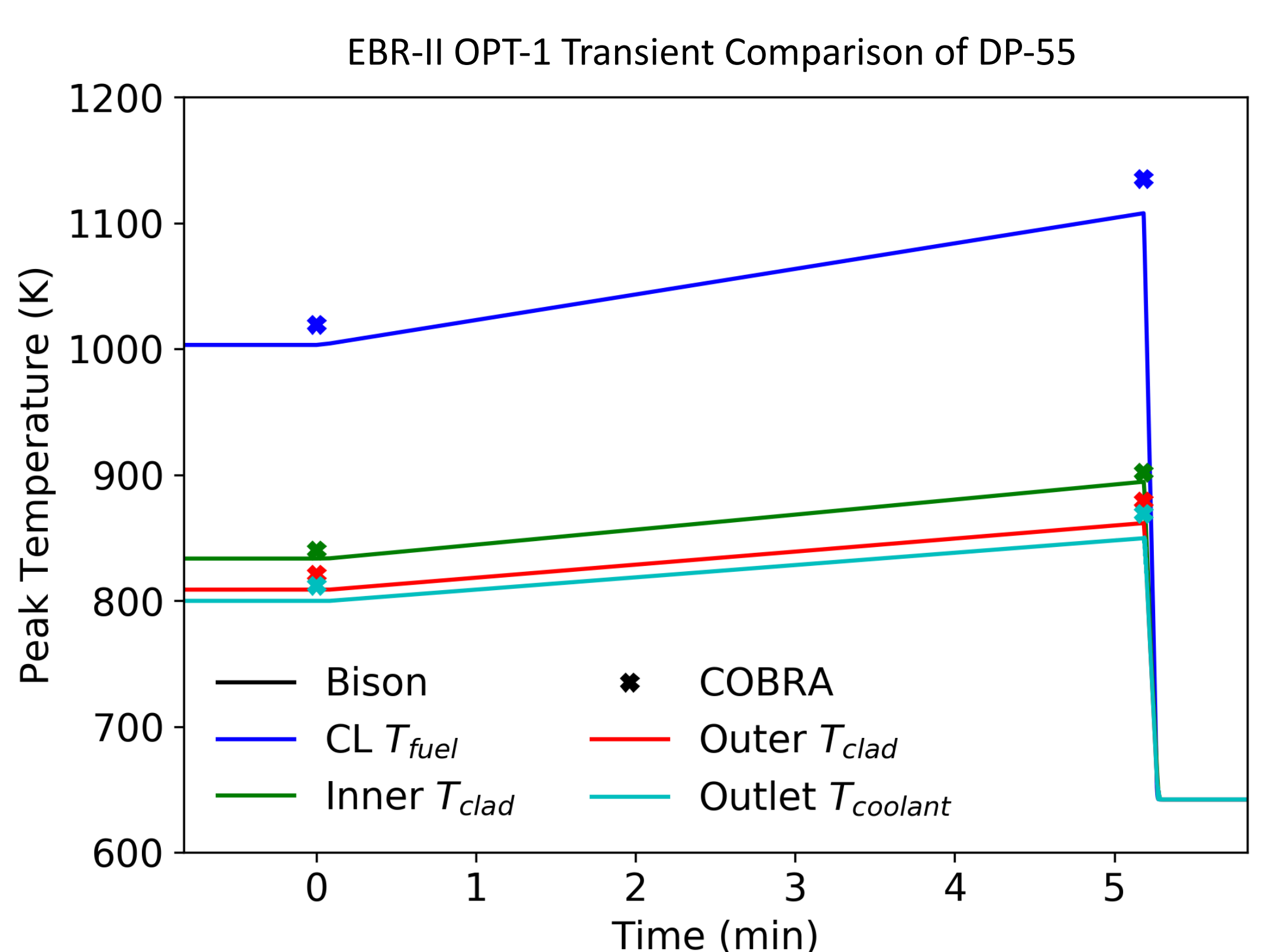

OPT-1 Characteristics

- Ternary fuel clad in HT9

- Linear power ramp at power to SCRAM

- EBR-II assembly sodium coolant channel

- Pin pre-irradiated in EBR-II
Bison Capability

$\checkmark$ Ternary and HT9 models

$\checkmark$ Power history with profile and coupling factors

$\checkmark$ Triangular sub-channel convection boundary

$\square$ Partially able to set initial conditions from irradiated sister pin's PIE data

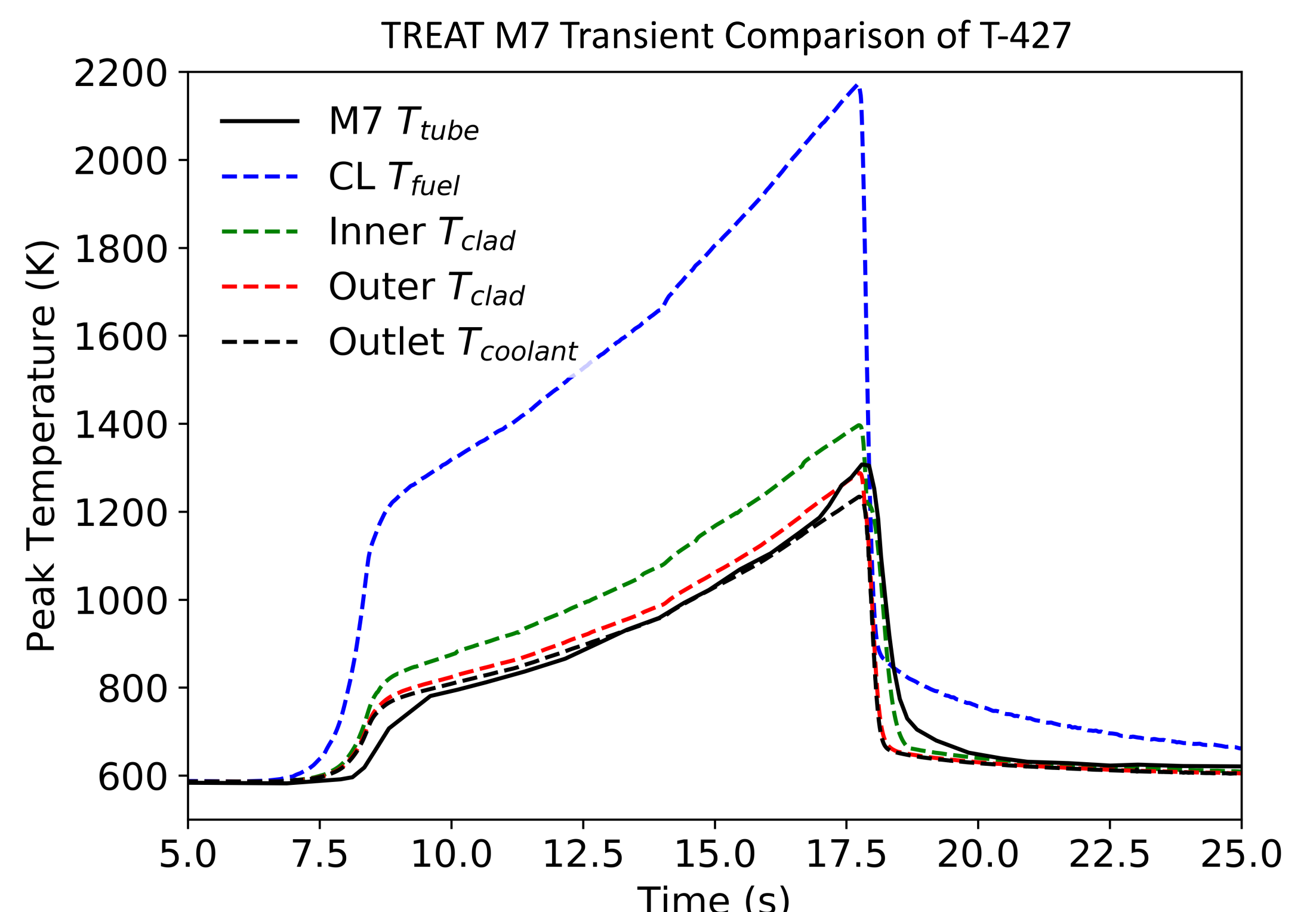

M7 Characteristics

- Binary fuel clad in HT9

- Shaped transient with SCRAM

- TREAT flowing sodium loop

- Zones of fuel melted
Bison Capability

$\checkmark$ Binary and HT9 models

$\checkmark$ Power history with profile and coupling factors

$\checkmark$ Tube sub-channel convection boundary

$\square$ Not able to model melting

Research Tools Used

$\mathrm{LAT}_{\mathrm{E}} \mathrm{X}$ matp $\circledast$ tib python

Serpent w
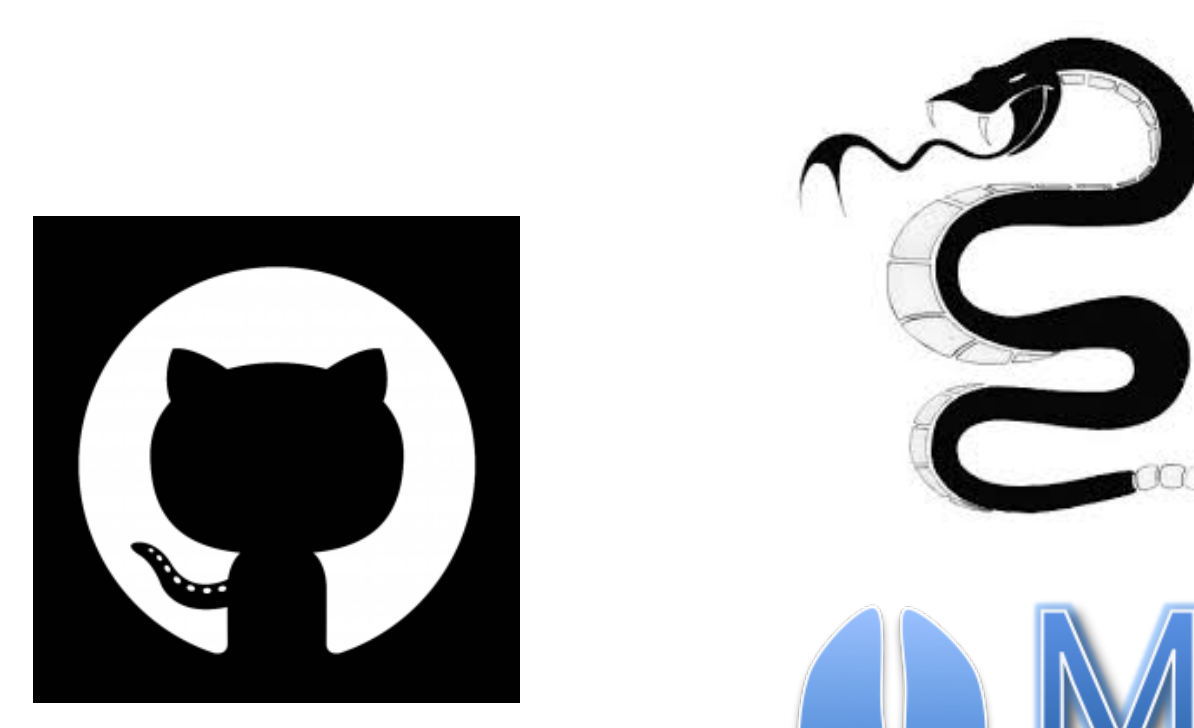

BASH 